This item was submitted to Loughborough's Research Repository by the author.

Items in Figshare are protected by copyright, with all rights reserved, unless otherwise indicated.

\title{
Talc as a nucleating agent and reinforcing filler in poly(lactic acid)
} \section{composites}

PLEASE CITE THE PUBLISHED VERSION

http://dx.doi.org/10.1002/pen.23543

PUBLISHER

John Wiley \& Sons, Inc @ Society of Plastics Engineers

VERSION

AM (Accepted Manuscript)

LICENCE

CC BY-NC-ND 4.0

\section{REPOSITORY RECORD}

Shakoor, Abdul, and Noreen L. Thomas. 2014. "Talc as a Nucleating Agent and Reinforcing Filler in Poly(lactic Acid) Composites”. figshare. https://hdl.handle.net/2134/13942. 
This item was submitted to Loughborough's Institutional Repository (https://dspace.lboro.ac.uk/) by the author and is made available under the following Creative Commons Licence conditions.

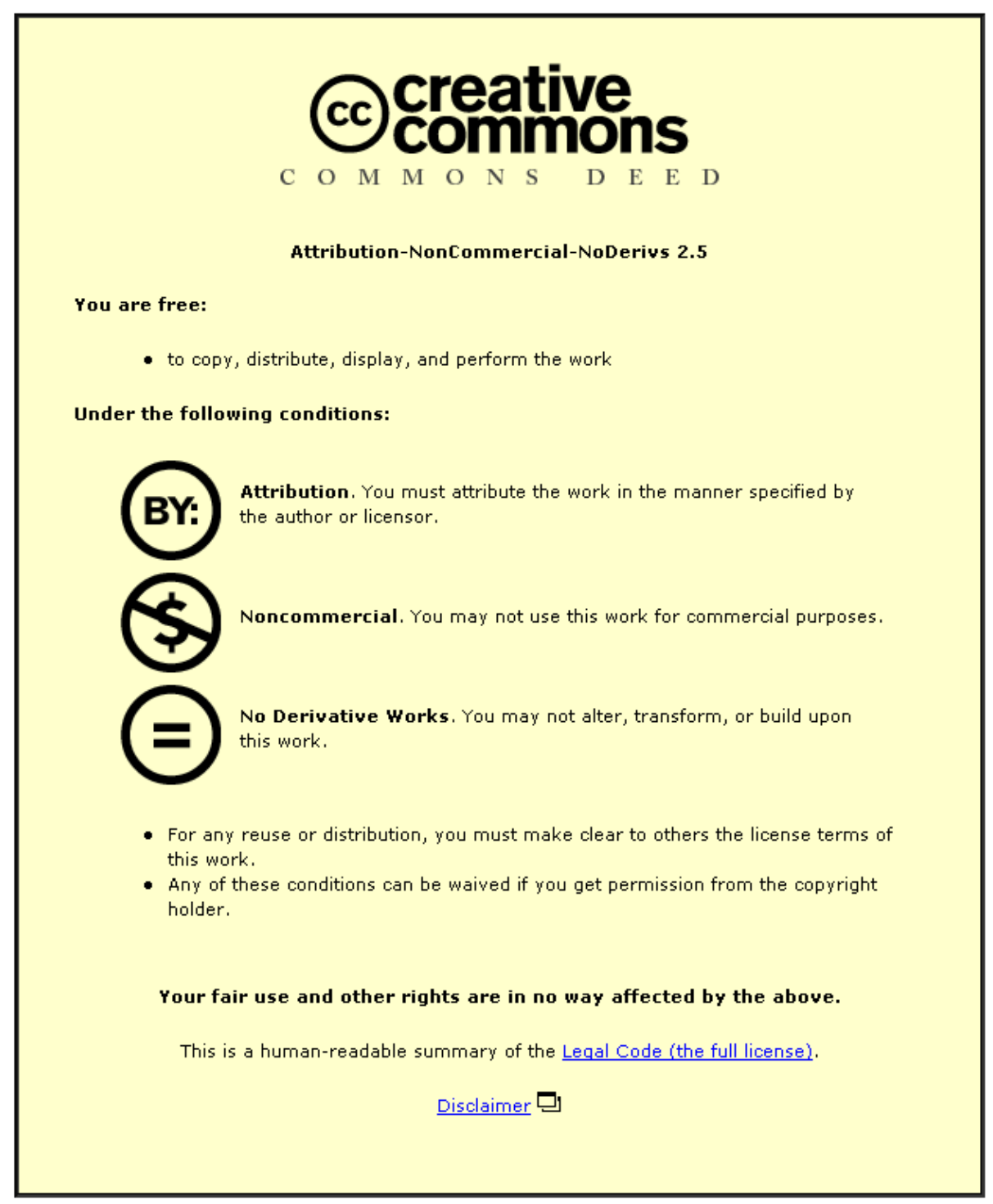

For the full text of this licence, please go to: http://creativecommons.org/licenses/by-nc-nd/2.5/ 


\title{
Talc as a Nucleating Agent and Reinforcing Filler in Poly Lactic Acid (PLA) Composites
}

\author{
A. Shakoor and N. L. Thomas, \\ Department of Materials, Loughborough University, Loughborough, Leicestershire, \\ LE11 3TU, UK
}

\begin{abstract}
The effect of talc on the crystallinity and mechanical properties of a series of polylactic acid (PLA) / talc composites has been investigated. The composites were prepared by melt blending followed by compression moulding. It was found that talc acted as a nucleating agent and increased the crystallinity of the PLA from 2\% to $25 \%$. There was significant improvement in Young's modulus of the composites with increasing talc addition and these results were found to fit the Halpin Tsai model. Thermo-mechanical tests confirmed that the combination of increased crystallinity and storage modulus leads to improvement in the heat distortion properties.
\end{abstract}

\section{INTRODUCTION}

Due to increased environmental awareness and a growing concern about the disposal of plastic waste, there has recently been a rising demand from consumers for biodegradable polymers. Many of these polymers are also derived from renewable resources, such as plant-based feedstocks or from bacterial fermentation. Hence these materials meet the requirement of being derived from replacements to fossil fuel feedstocks in addition to addressing growing concerns about end-of-life disposal issues and the need to find alternatives to landfill.

One such polymer is poly(lactic acid) (PLA) $)^{1,2}$. It is a versatile, compostable polymer, produced from lactic acid that is obtained by fermentation of carbohydrate, which is derived from renewable resources such as corn and sugar beet. PLA is produced commercially by ring-opening polymerisation of the lactide, which is a cyclic ester composed of two lactic acid units. Lactic acid contains an asymmetric carbon atom and therefore exists in two optically active isomers ( $D$ and L). Hence three optically 
isomeric forms of lactide are possible: L-lactide (a dimer of L-lactic acid), D-lactide (a dimer of D-lactic acid) and meso-lactide (a dimer of L- and D-lactic acid). The crystallisable content of PLA is determined by the ratio of L-, D- and meso- lactide in the polymer: higher crystallinities are obtained with the more optically pure polymers because of their higher chain symmetry. PLA also has a very slow rate of crystallisation, which allows for a greater control over the crystalline content.

A major issue restricting the use of PLA is its poor technical performance compared with many conventional polymers, particularly with respect to mechanical properties and heat distortion temperature (HDT). For this reason a number of different strategies have been adopted to improve the properties of PLA: these include both blending PLA with other bioplastics and the incorporation of additives, such as fillers and nanofillers, to produce composite materials. For example, PLA has been blended with poly(caprolactone) (PCL) to increase its flexibility ${ }^{3,4}$ and with poly(hydroxybutyrate) (PHB) to improve tensile properties and biodegradability ${ }^{5}$. There is much interest in PLA nanocomposites because of the potential of montmorrillonite nanofillers to improve the mechanical, barrier and biodegradation properties of PLA ${ }^{6,7}$. More conventional fillers, such as talc, have been used for many years as reinforcing fillers and nucleating agents in commodity polymers and talc has the potential to provide significant and cost-effective improvements in PLA formulations.

Talc is a hydrated magnesium silicate with the formula $\mathrm{Mg}_{3} \mathrm{SiO}_{10}(\mathrm{OH})_{2}{ }^{8}$. It has a plate-like structure held together by weak Van der Waal's forces, so that the talc platelets can be delaminated at low shear stresses and are easy to disperse. Most commonly, talc is added as a filler to isotactic poly(propylene) (PP). At low concentrations (less than 3 weight \%) it acts as a nucleating agent, reducing spherulite size and shortening processing time ${ }^{9}$. At higher loadings $(10-40$ weight $\%)$ it acts as a reinforcing filler, increasing tensile modulus and stiffness, but reducing strain-tobreak and impact strength ${ }^{10}$.

Talc has also been added as a filler to PLA. Addition of $2 \%$ talc was found to reduce crystallisation half-times and resulted in a significant increase in crystallinity and decreased processing time ${ }^{11}$. Jain et al ${ }^{4}$ investigated adding talc $(1-5$ weight $\%)$ to 
blends of PLA and PCL. It was found that talc improved the miscibility and adhesion between the PCL bulk phase and the PLA domains. Values of tensile and storage modulus increased linearly with the talc loading. Fowlks and Narayan ${ }^{12}$ have investigated PLA-talc composites compatibilized with maleic anhydridefunctionalized PLA, which acted as an interfacial additive and increased adhesion between the PLA matrix and the talc filler.

In the current study, talc has been melt processed with PLA at addition levels of 10, 20 and 30 weight $\%$. The morphology, thermal properties and mechanical properties of these blends have been investigated. The aim of the study is to examine how talc affects the crystallisability of PLA, to investigate the dispersion of the talc in the PLA matrix and to model the effect of talc on the tensile modulus (Young's modulus) of the composites.

\section{EXPERIMENTAL}

\section{Materials}

PLA granules (HM1011) were supplied by Hycail BV (now Tate \& Lyle, London, UK). The weight average molecular weight $\left(\mathrm{M}_{\mathrm{w}}\right)$ of the PLA was found to be $224 \mathrm{x}$ $10^{3} \mathrm{~g} / \mathrm{mol}$ as determined by gel permeation chromatography (GPC). Its specific gravity was $1.24 \mathrm{~g} / \mathrm{cm}^{3}$.

Talc (JetFine 3CC) was supplied by Luzenac (now Imerys Talc, Toulouse, France). The talc had a median diameter $0.9 \mu \mathrm{m}$, a moisture level of $0.1 \%$ and a specific gravity of $2.8 \mathrm{~g} / \mathrm{cm}^{3}$.

\section{Preparation and Processing of the PLA/Talc Composites}

Before processing, the PLA granules were dried at $70^{\circ} \mathrm{C}$ overnight $(16 \mathrm{hrs})$ in a vacuum oven to remove excess moisture. Composites of PLA and talc were prepared with the following PLA/talc concentrations: 100/0, 90/10, 80/20, 70/30 by weight. Melt blending was carried out in a Haake Polylab torque rheometer at $170^{\circ} \mathrm{C}$ for 10 minutes with a constant rotor speed of $60 \mathrm{rpm}$. Samples for differential scanning calorimetry (DSC), tensile testing and dynamic mechanical analysis were all prepared 
by compression moulding in a 20 ton hydraulic press. The materials were hot pressed at $180^{\circ} \mathrm{C}$ for three minutes at $10 \sim 12$ tons pressure followed by quenching to room temperature over a period of three minutes at the same pressure level.

\section{Differential Scanning Calorimetry (DSC)}

The melting and crystallization behaviours of the composites were investigated using DSC. Measurements were performed using a DSC Q200 (TA Instruments, USA) fitted with an autosampler and mechanical cooler. Samples of approximately 10 16 $\mathrm{mg}$ in mass were put into sealed aluminium pans and loaded into the autosampler. The machine was run on heat-cool-heat mode and data was analysed using the TA universal analysis software package. The samples were heated from $0^{\circ} \mathrm{C}$ to $200^{\circ} \mathrm{C}$ at $10^{\circ} \mathrm{C} / \mathrm{min}$ and left for 1 minute to measure the melting point of the as-formed samples, then cooled down to $0^{\circ} \mathrm{C}$ at the same rate to determine the crystallinity. Then the samples were reheated to $200^{\circ} \mathrm{C}$ at $10^{\circ} \mathrm{C} / \mathrm{min}$ to study the melting and degradation behaviour. All the values represent the average of 3 samples. The amount of overall crystallinity was calculated using Equation 1.

$$
\% \text { Crystallinity }=\left[\frac{\Delta H_{m}-\Delta H_{c}}{93.1 * w}\right] * 100 \%
$$

In Equation 1, $\Delta \mathrm{H}_{\mathrm{m}}(\mathrm{j} / \mathrm{g})$, is the measured heat of fusion (melting enthalpy), $\Delta \mathrm{H}_{\mathrm{c}}(\mathrm{j} / \mathrm{g})$ is the enthalpy of cold crystallization and $93.1(\mathrm{j} / \mathrm{g})$ is the enthalpy of fusion for 100 $\%$ crystalline PLA. For composites of PLA, the weight fraction of the PLA (w) needs to be considered in calculating the percent crystallinity.

\section{Tensile Testing}

Tensile testing was carried out using a Tinius Olsen H50 KS testing machine with a clip-on extensometer to measure the modulus more precisely. The machine was equipped with a load cell of $5 \mathrm{kN}$. Compression moulded dumbbell-shaped tensile specimens (width $10 \mathrm{~mm}$, thickness $3 \mathrm{~mm}$, length $60 \mathrm{~mm}$ ) were extended at a crosshead speed of $10 \mathrm{~mm} / \mathrm{min}$. The Young's modulus, tensile strength and strain at break were measured. All results presented are mean values of five to seven measurements. 


\section{Dynamic Mechanical Analysis (DMA)}

Viscoelastic properties of the PLA/talc composites were investigated using dynamic mechanical analysis (DMA). DMA Q800 apparatus (TA Instrument Inc, USA) was used to measure the storage modulus, loss modulus and $\tan \delta$ of each composite sample as a function of temperature. The storage modulus is the elastic component and the loss modulus is the viscous component in the viscoelastic response of the polymer to dynamic loading conditions. All samples were tested in the flexure (dualcantilever bending) mode. The rectangular specimens (width $12 \mathrm{~mm}$, thickness $3 \mathrm{~mm}$, length $64 \mathrm{~mm}$ ) were heated at a constant rate of $3^{\circ} \mathrm{C} / \mathrm{min}$ from room temperature to $140^{\circ} \mathrm{C}$ and tested at a frequency of $1 \mathrm{~Hz}$.

\section{Morphology}

The morphology of the talc and the fracture surfaces of the PLA/talc composites were examined using a scanning electron microscope equipped with a field emission gun (FEGSEM, LEO 1530 VP). The samples were gold coated before examination. In addition the distribution of talc in the PLA/talc composites was examined in the FEGSEM using the back-scattered electron mode.

Transmission electron microscopy (TEM, JEOL 2100 FX) was used to investigate the aspect ratio of the talc filler in the composites. Samples were prepared by first encapsulating in epoxy resin. After the resin was cured, thin sections were cut with an ultra-microtome using a diamond knife. These sections were mounted on copper grids for mounting into the TEM. The aspect ratio of the talc filler within the PLA matrix was measured from the TEM micrographs using Image $\mathrm{J}^{\circledR}$ software.

\section{RESULTS AND DISCUSSION}

\section{Differential Scanning Calorimetry (DSC)}

The DSC profiles of the PLA/talc composites are shown in Figure 1. The heating scan (Figure 1a) shows the glass transition temperature and the exothermic and endothermic peaks derived from cold crystallization of the amorphous phase and the 
melting peak respectively. The second heating scans of the various composites are given in Figure 1a.

Data from the heating scans are summarised in Table 1. It can be seen that there is a slight increase in the glass transition temperature $\left(\mathrm{T}_{\mathrm{g}}\right)$ of the PLA from $54^{\circ} \mathrm{C}$ to $57^{\circ} \mathrm{C}$ on addition of the talc filler, presumably due to a constraint on free volume of the polymer by the introduction of a platy filler. The cold crystallization temperature $\left(T_{c}\right)$ is reduced from $127^{\circ} \mathrm{C}$ for the pure PLA to $96^{\circ} \mathrm{C}$ for the PLA/talc composites indicating a nucleating effect by the talc filler. However, the extent of cold crystallization is greatly reduced - from $22 \%$ for pure PLA to $5.6 \%$ for the $90 / 10$ composite and then down to $0.7 \%$ and $0 \%$ for the $80 / 20$ and $70 / 30$ composites respectively.

The melting temperature $\left(\mathrm{T}_{\mathrm{m}}\right)$ of the pure PLA is about $155^{\circ} \mathrm{C}$, as indicated by the single peak in Figure 1a. In the presence of the talc filler, the melting of the crystalline phase is characterised by a double peak, which becomes more pronounced with a higher concentration of talc. The double peak denotes two different crystalline or spherulitic forms. The second peak is around $150^{\circ} \mathrm{C}$ signifying a less thermally stable phase. Other workers have also reported a double peak in the melting endotherm of PLA for both pure PLA ${ }^{13}$ and PLA composites ${ }^{4}$.

Also included in Table 1 are data on the \% crystallinity, as calculated using equation 1 above. It is seen that the pure PLA is essentially amorphous with a crystallinity of only $2 \%$, whereas addition of $10 \mathrm{wt} \%$ of talc increases the crystallinity to $25 \%$. Addition of $30 \mathrm{wt} \%$ talc gives only a slight further increase in crystallinity up to $27 \%$. It is clear from these data that talc acts as a nucleating agent for the crystallization of PLA. Further evidence is provided by the DSC cooling scans shown in Figure $1 \mathrm{~b}$. Here it can be seen that pure PLA is amorphous, with no crystallisation peak, whereas addition of talc gives rise to an exothermic crystallisation peak in the cooling scan. Increasing the talc content gives rise to a more pronounced crystallisation exotherm.

It is well known that talc acts as a nucleating agent when added to isotactic polypropylene homopolymer or copolymer ${ }^{9}$, where it has been shown to increase the crystallisation temperature and nucleation density and reduce the spherulite size. 
Harris and Lee ${ }^{11}$ have also reported that talc can act as a nucleating agent to control the crystallinity of PLA and hence improve mechanical properties. The reason for the specific role of talc (as opposed to other inorganic fillers) in promoting spherulite nucleation of polypropylene has been attributed ${ }^{8}$ to matching of the (001) talc plane with a specific crystallographic direction in the isotactic polypropylene and it is proposed that hexagonal rings on the talc surface form hydrogen bonds with methyl groupings in the PP. In a similar way, it is likely that crystallographic matching would account for the role of talc in promoting crystallinity in PLA.

\section{Mechanical Properties}

The tensile properties of PLA and PLA/talc composites are shown in Table 2. All samples exhibited brittle failure. It can be seen from the table that there is no significant change to the tensile strength of the formulations because the results are within the experimental variation of the data. There is, however, found to be a significant reduction in elongation to break of the samples from $3.8 \%$ for pure PLA to $2.0 \%$ for $70 / 30 \mathrm{PLA} /$ talc. A reduction in elongation to break implies that the composites have become more brittle with the talc addition. Other workers have also reported a drop in \% elongation when talc is added to PLA based composites ${ }^{4,12}$. The most likely reason for the drop is that the addition of platy filler to a brittle polymer is causing stress concentration and crack initiation and therefore reducing toughness.

From Table 2 it is seen that there is a very significant increase in Young's modulus from a value of $4.1 \mathrm{GPa}$ for the pure PLA up to $9.8 \mathrm{GPa}$ on addition of $30 \mathrm{wt} \%$ of talc. This effect is due to the addition of a high modulus platy filler to a lower modulus polymer.

Different theoretical models can be applied to predict the reinforcing effect on Young's modulus of particulate composites. Due to the platy structure of the filler, the geometrical parameters of the filler will affect the properties of the composite. Of particular importance is the aspect ratio (L/D) of the filler, which is the ratio of length (L) to thickness (D) of the filler particles. The Halpin-Tsai equation ${ }^{14}$ takes into account the effect of filler geometry in predicting the modulus of the composite materials. The Halpin-Tsai equation is given in equation 2 below. 


$$
\frac{E_{c}}{E_{m}}=\frac{\left(1+A B \phi_{f}\right)}{\left(1-B \phi_{f}\right)}
$$

Where, $E_{c}$ is the Young's modulus of the composite, $E_{m}$ is the Young's modulus of the matrix, $E_{\mathrm{f}}$ is the Young's modulus of the filler, $\varphi_{\mathrm{f}}$ is the volume fraction of the filler, $\mathrm{A}=2(\mathrm{~L} / \mathrm{D})$ and $\mathrm{B}=(\mathrm{R}-1) /(\mathrm{R}+\mathrm{A})$, where $\mathrm{R}=\mathrm{E}_{\mathrm{f}} / \mathrm{E}_{\mathrm{m}}$. In calculating the predicted value of the Young's modulus of the various PLA/talc composites from the Halpin Tsai equation, the following values have been used: $\mathrm{E}_{\mathrm{m}}$ is $4.1 \mathrm{GPa}$ as measured, $\mathrm{Ef}$ is taken as $70 \mathrm{GPa}$ which is the elastic modulus of other silicate fillers (such as glass), $\varphi_{\mathrm{f}}$ is calculated from the weight fraction using the values of the density of PLA of 1.24 $\mathrm{g} / \mathrm{cm}^{3}$ and the density of talc as $2.8 \mathrm{~g} / \mathrm{cm}^{3}$. The aspect ratio of the talc was measured from the TEM cross-sections shown in Figure 2 and the average value was found to be 8 .

Experimental measurements of the tensile modulus of the PLA/talc composites are plotted in Figure 3 and superimposed on these data is the theoretical prediction from the Halpin Tsai model. There is seen to be a good fit between the Halpin Tsai prediction and the experimental data.

\section{Morphology}

The morphology of the talc is shown in the scanning electron micrograph of Figure 4, where it can be seen to have a plate-like shape. The JetFine 3CC talc has a median diameter of $0.9 \mu \mathrm{m}$, which is in the category of ultra-fine talc.

Figures 5(a) and (b) show backscattered electron images of the surfaces of the compression moulded PLA/talc composites containing $20 \mathrm{wt} \%$ and $30 \mathrm{wt} \%$ of talc respectively. Because of the atomic number contrast in the backscattered electron image, it is possible to see the distribution of the talc particles in the PLA matrix. These images indicate that the talc particles are uniformly distributed and have tended to align parallel to the sample surface.

Transmission electron micrographs of cross-sections through the samples containing $10 \mathrm{wt} \%$ and $30 \mathrm{wt} \%$ talc are shown in Figures 2 (a) and (b) respectively. These images 
also show that the talc particles are well distributed within the polymer matrix and have predominantly aligned along the flow direction of the polymer melt.

Fracture surfaces of the PLA/talc composites containing $10 \mathrm{wt} \%, 20 \mathrm{wt} \%$ and $30 \mathrm{wt} \%$ of talc are shown in Figures 6(a), (b) and (c) respectively. These micrographs confirm the brittle nature of the failure in the tensile test. There is evidence of pull-out of some talc particles from the surface. The talc was not coated with any coupling agent, so although it is well distributed because of its relatively hydrophobic surface, there is not good surface adhesion between the talc and the polymer matrix.

\section{Dynamic Mechanical Analysis (DMA)}

The temperature dependence of the dynamic storage modulus of PLA and PLA/talc composites is given in Figure 7, which is a plot of the logarithm of the storage modulus as a function of temperature. It is clear from the plot that addition of talc to the PLA matrix gives a very significant increase in the storage modulus of the samples, depending on the amount of talc added. Values of the flexural storage modulus at $30^{\circ} \mathrm{C}$ are given in Table 3 and show that measured values increase from 2.3 GPa for PLA up to 3.9, 4.9 and $6.2 \mathrm{GPa}$ on the addition of 10,20 and $30 \mathrm{wt} \%$ talc respectively, which is in line with the increases discussed above for the tensile moduli.

Figure 7 also shows that the storage moduli of the PLA and PLA/composites remain almost constant at temperatures below the glass transition temperature (up to about $60^{\circ} \mathrm{C}$ ) and then drop at the $\mathrm{T}_{\mathrm{g}}$, as would be expected for an amorphous polymer. It is seen that for all the samples, as the temperature continues to increase, the drop in storage modulus is arrested and the modulus starts to increase again. This is due to the recrystallisation of the PLA. The extent to which this happens is determined by the amount of talc present: the greater the amount the lower the temperature at which recrystallisation takes place. This confirms the earlier observations made in the DSC tests that talc acts as a nucleating agent for the crystallisation of PLA. This observation has implications for the softening and heat distortion of PLA. The fact that talc acts as both a reinforcing filler and a nucleating agent for recrystallisation of 
PLA, implies that it is a useful additive to increase the heat distortion temperature (HDT) of PLA.

Figure 8 is a plot of Tan Delta (Tan $\delta$ ) as a function of temperature. Tan $\delta$ is the loss factor, which is the ratio of the loss modulus to the storage modulus. It describes the extent of viscous dissipation of energy in a polymer and is related to molecular motion. There is a particularly strong damping at the glass transition because the large increase in volume that occurs above $\mathrm{T}_{\mathrm{g}}$ allows space for molecular motion to take place. Hence the main peak in the Tan $\delta$ versus temperature plot corresponds to the $T_{g}$ of the polymer. It is seen in Figure 8 that there is a small but significant shift in the peak position to a higher value when talc is added to the PLA/talc matrix. The values of $\mathrm{T}_{\mathrm{g}}$ as found from the DMA Tan $\delta$ peaks are given in Table 3. As in the case of the DSC results, this small increase in $T_{g}$ on the addition of significant amounts of talc to PLA can be interpreted in terms of a constraint on the mobility of the polymer chains by addition of a platy filler. Another factor to observe from Figure 8 is that the area under the Tan $\delta$ peaks decreases with increasing talc content and this implies a reduced damping capability in the composites with increasing talc addition. This also ties in with the reduction in elongation-to-break found in the mechanical property measurements.

\section{CONCLUSIONS}

This study has investigated the crystallization behaviour, morphology, tensile properties and thermo-mechanical properties of PLA/talc composites at weight ratios of 100/0, 90/10, 80/20 and 70/30. The following conclusions have been drawn.

The DSC heating scans showed that the cold crystallization temperature $\left(T_{c}\right)$ was reduced from $127^{\circ} \mathrm{C}$ for the pure PLA to $96^{\circ} \mathrm{C}$ for the PLA/talc composites demonstrating a nucleating effect by the talc filler. The pure PLA was found to be essentially amorphous with a crystallinity of only $2 \%$, whereas the crystallinity increased to $25 \%$ after addition of talc. Further evidence that talc acts as a nucleation agent was found from the DSC cooling scans: pure PLA was amorphous, with no crystallisation peak, whereas addition of talc gave rise to an exothermic crystallisation peak in the cooling scan. 
Morphology of the composites was observed by both scanning and transmission electron microscopy. The talc particles were seen to be uniformly distributed and predominantly aligned along the flow direction of the polymer melt. The aspect ratio of the ultra-fine talc particles dispersed in the PLA matrix was measured from the transmission electron micrographs and found to be an average value of 8 .

All samples exhibited brittle failure in tensile testing. There was a significant increase in Young's modulus from a value of $4.1 \mathrm{GPa}$ for the pure PLA up to 5.8, 7.0 and 9.8 GPa on addition of 10, 20 and 30 weight \% of talc respectively. There was found to be a good fit between these data and the theoretical prediction from the Halpin Tsai model.

The DMA results showed a very significant increase in the storage modulus of the samples, depending on the amount of talc added. Above Tg there is an increase in modulus for samples containing talc, due to the recrystallisation of the PLA caused by the nucleating effect of the talc. The results indicate that talc is a useful additive to increase the heat distortion temperature (HDT) of PLA because it acts as both reinforcing filler and a nucleating agent

\section{ACKNOWLEDGEMENTS}

The authors would like to acknowledge technical assistance from Mr. John Bates and Dr. Keith Yendall, Department of Materials, Loughborough University, for transmission electron microscopy (TEM) and scanning electron microscopy (SEM) respectively.

The authors would also like to acknowledge sponsorship for this project from the University of Engineering \& Technology, Peshawar, Khyber Pakhtunkhwa, Pakistan. 


\section{REFRENCES}

1. R. Auras, B. Harte and S. Selke, Macromol Biosci, 4, 835-864 (2004).

2. D. Garlotta, Journal of Polymers and the Environment, 9, 63 - 84 (2001).

3. C. L. Simões, J. C. Viana and A. M. Cunha, Journal of Applied Polymer Science, 112, 345-352 (2009).

4. S. Jain, M. M. Reddy, A. K. Mohanty, M. Misra and A. K. Ghosh, Macromolecular Materials and Engineering, 295, 750-762 (2010).

5. M. Zhang and N. L. Thomas, Advances in Polymer Technology, 30, 67-79 (2011).

6. S. S. Ray, K. Yamada, M. Okamoto and K. Ueda, Nano Letters, 2, 1093 1096 (2002).

7. A. R. McLauchlin and N. L. Thomas, Polymer Degradation and Stability, 94, 868-872 (2009).

8. E. Ferrage, F. Martin, A. Boudet, S. Petit, G. Fourty, F. Jouffret, P. Micoud, P. De Parseval, S. Salvi, C. Bourgerette, J. Ferret, Y. Saint-Gerard, S. Buratto and J. P. Fortune, Journal of Materials Science, 37, 1561-1573 (2002).

9. B. Fillon, A. Thierry, B. Lotz and J. C. Wittmann, Journal of Thermal Analysis, 42, 721-731 (1994).

10. S. N. Maiti and K. K. Sharma, Journal of Materials Science, 27, 4605-4613 (1992)

11. A. M. Harris and E. C. Lee, Journal of applied polymer science, 107, 22462255 (2008).

12. A. C. Fowlks and R. Narayan, Journal of Applied Polymer Science, 118, 28102820 (2010).

13. T. Tabi, I. E. Sajo, F. Szabo, A. S. Luyt and J. G. Kovacs, Express Polymer Letters, 4, 659-668 (2010).

14. L. Mascia, Thermoplastics: Materials Engineering, Elsevier Applied Science, London, 1989, P91. 


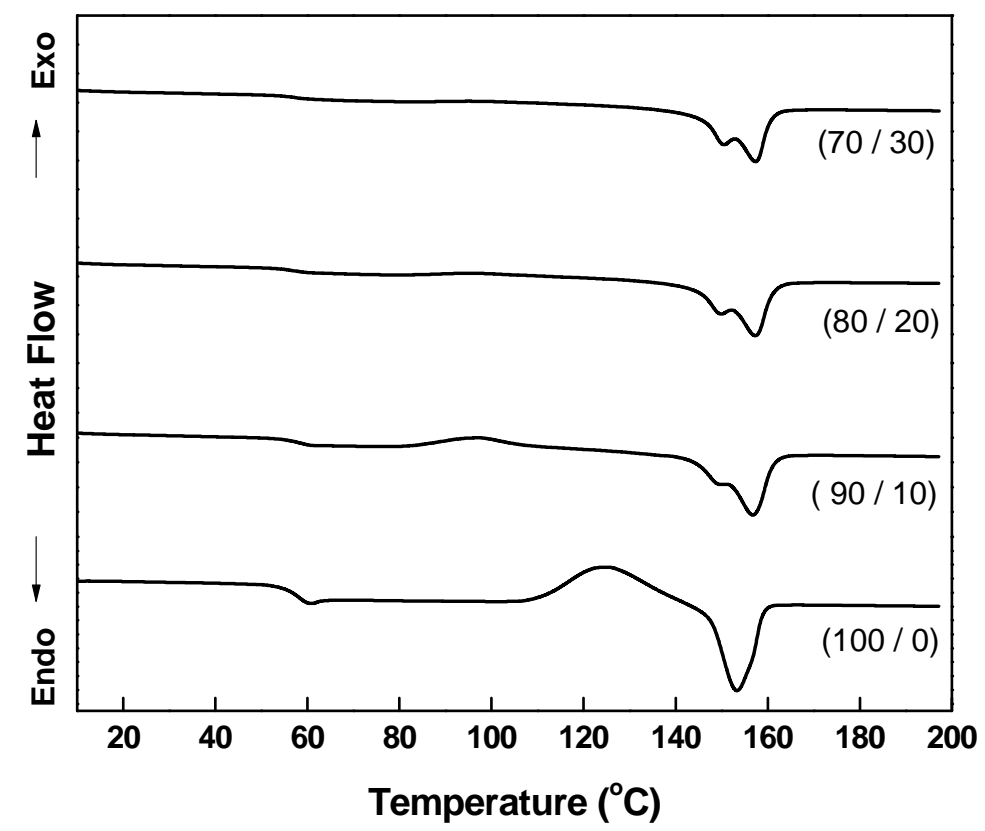

Figure 1(a): DSC heating Scans of PLA / Talc Composites

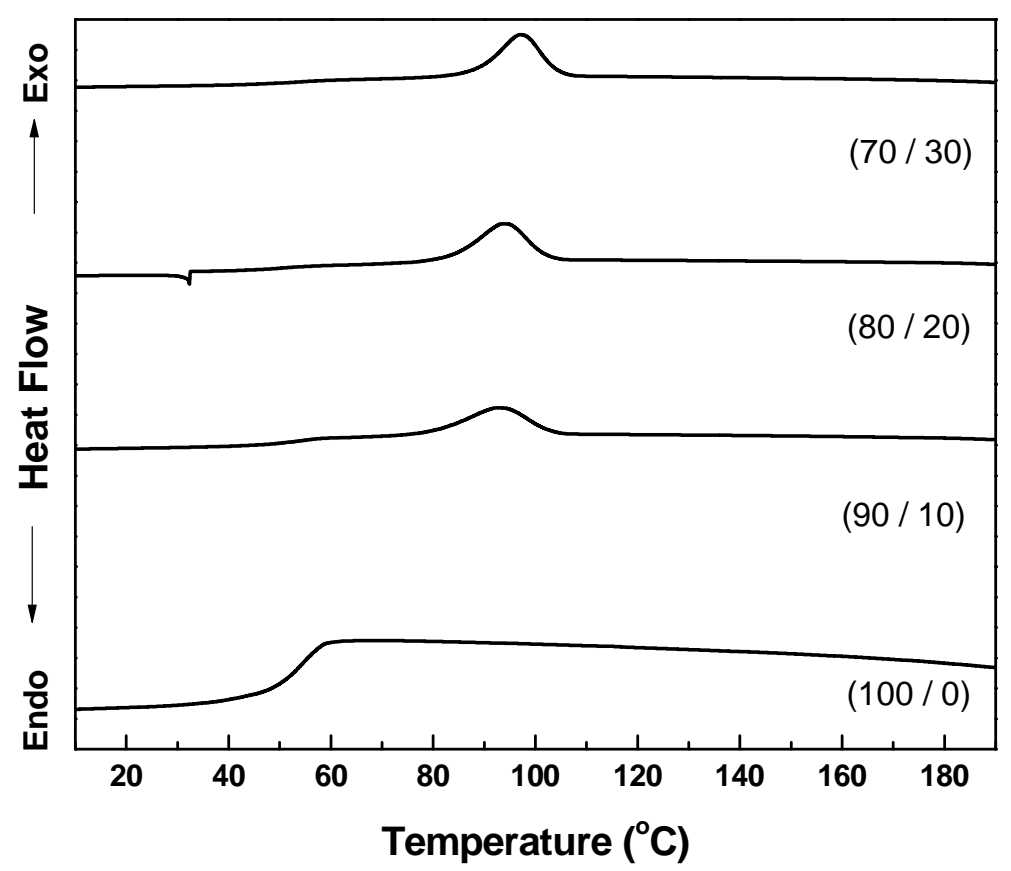

Figure 1(b): DSC cooling Scans of PLA/ Talc Composites 
(a)

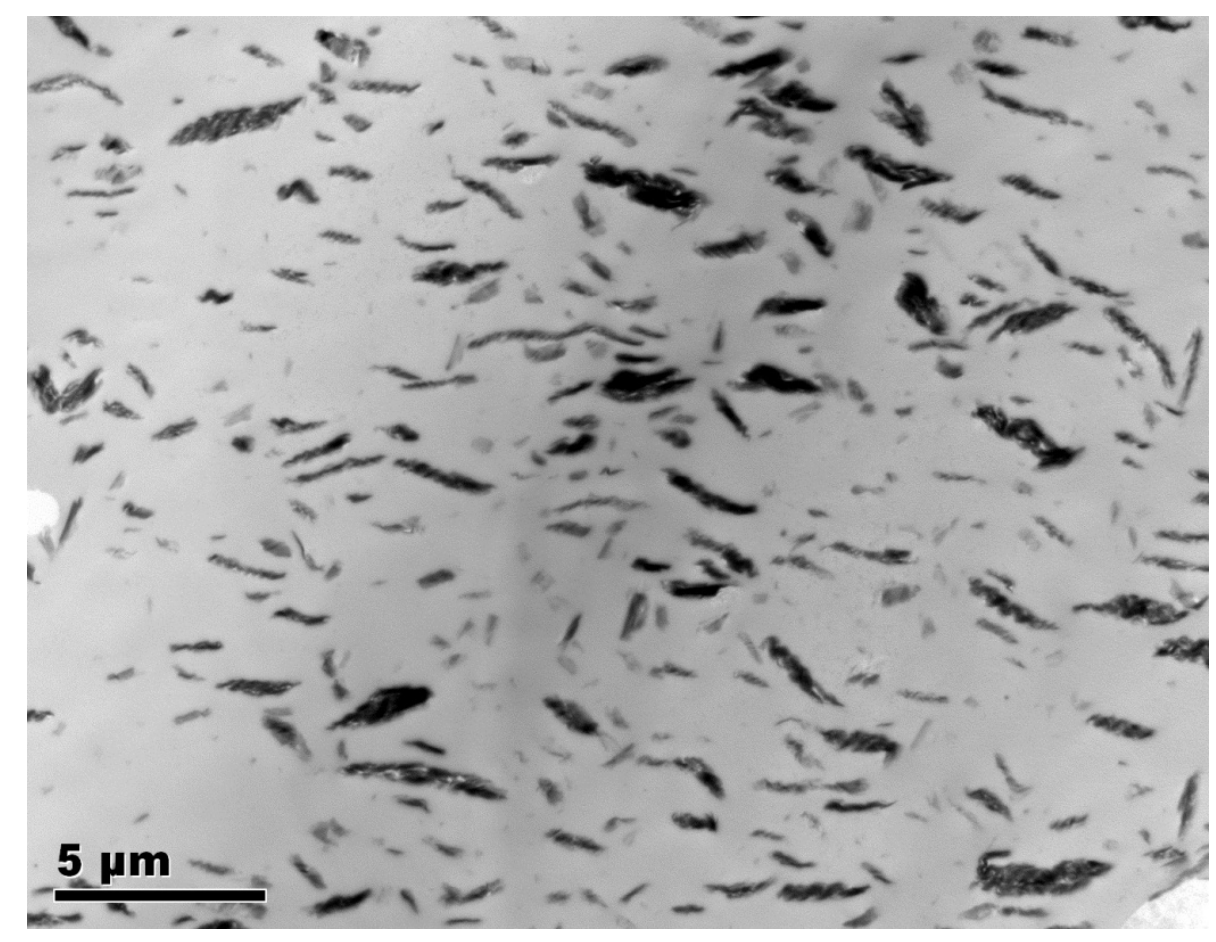

(b)

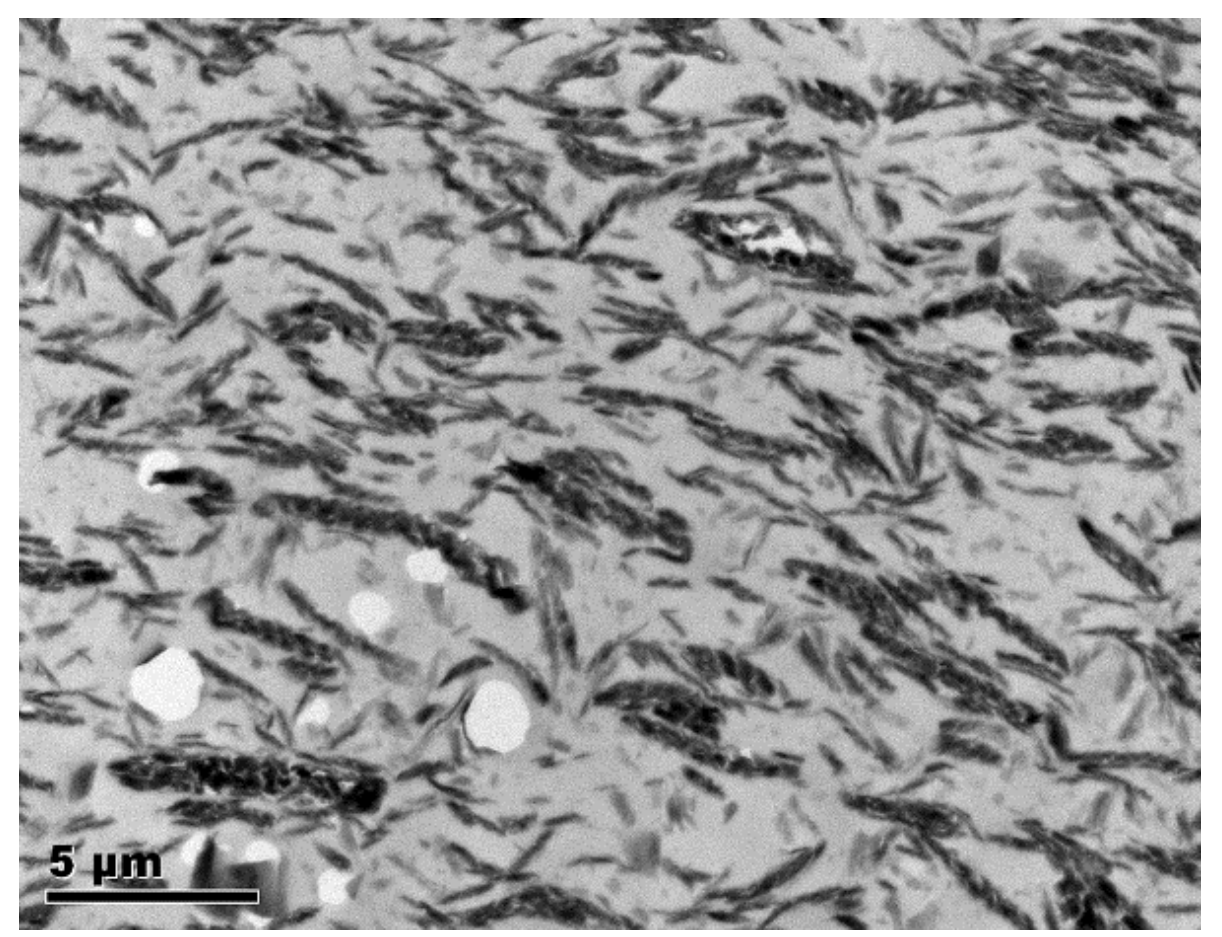

Figure 2: TEM Micrographs of PLA / Talc Composites (a) 90/10, (b) 70/30 


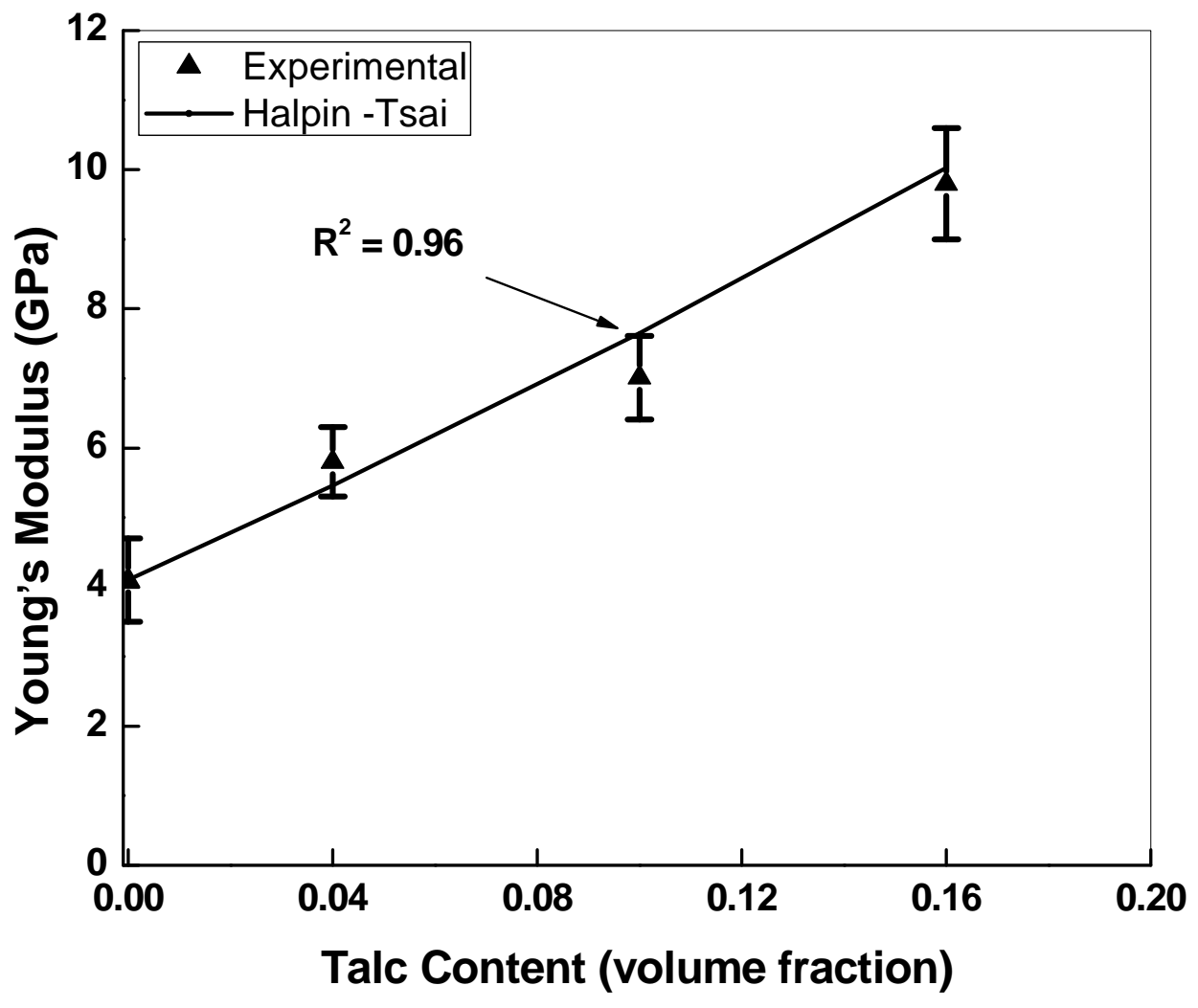

Figure 2 : Comparison of Experimental Data with the Haplin-Tsai model 


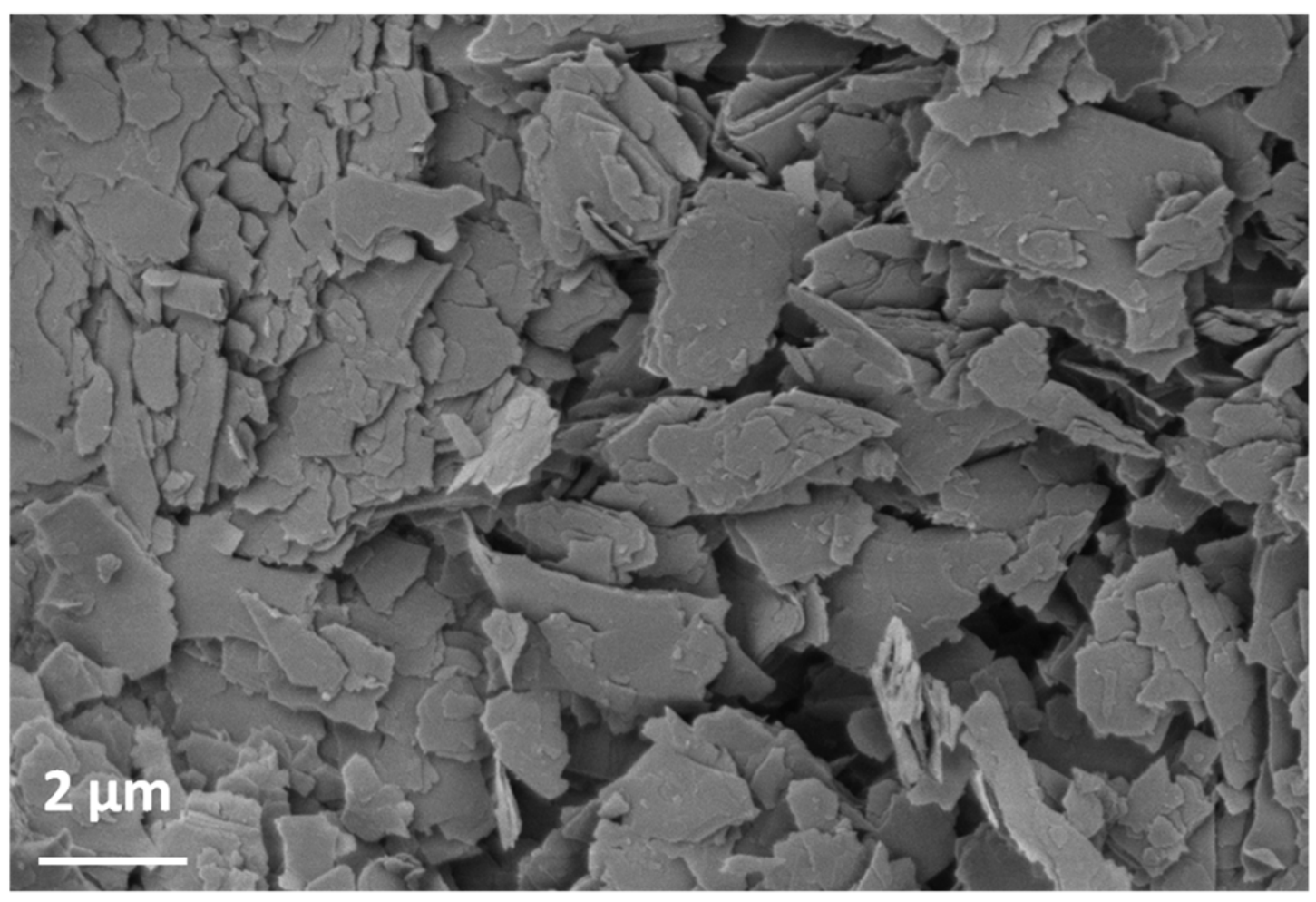

Figure 4: SEM Morphology of Pure Talc (Jet fine 3CC) 


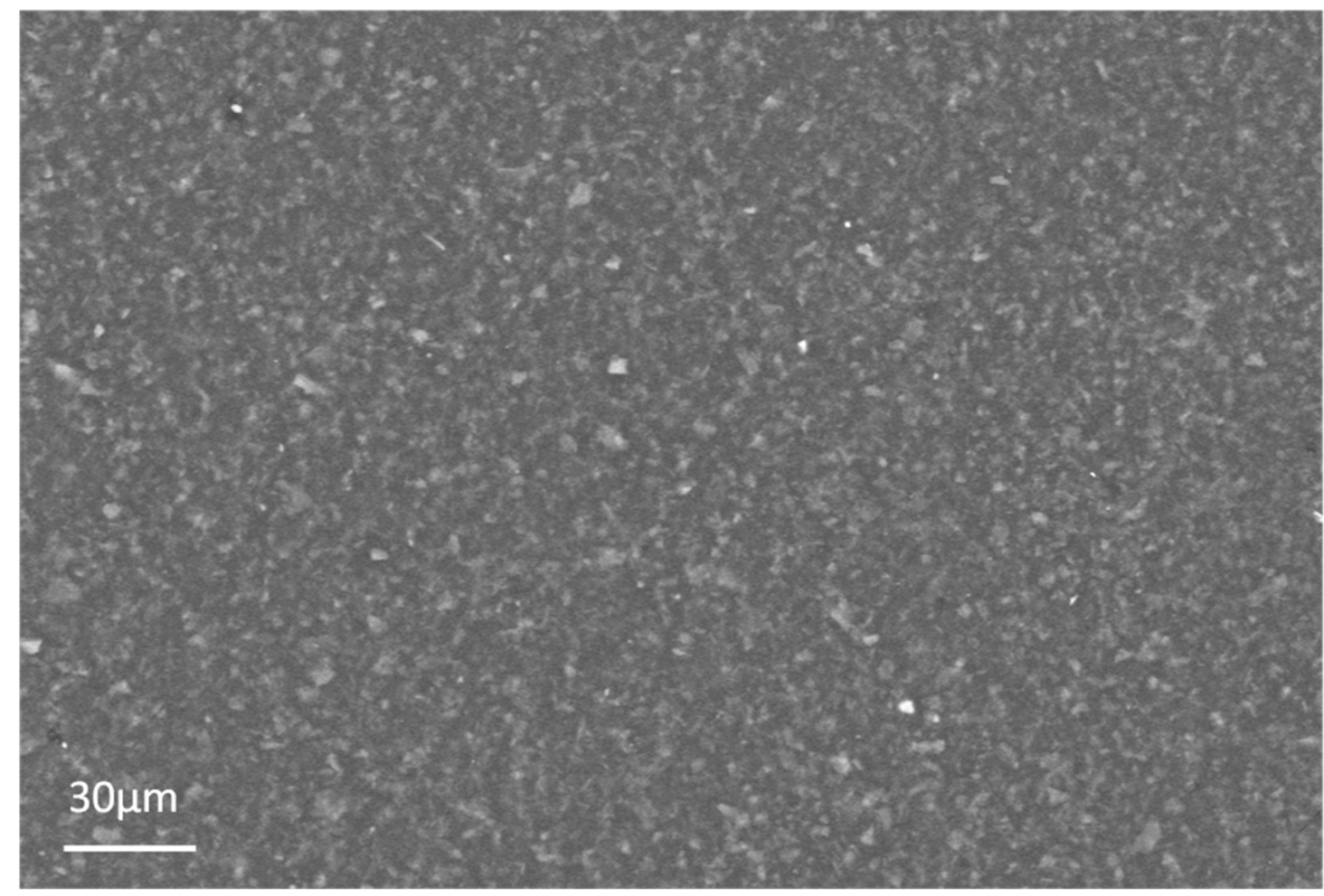

Figure 5(a): Backscattered SEM micrograph of PLA / Talc composite (80 / 20)

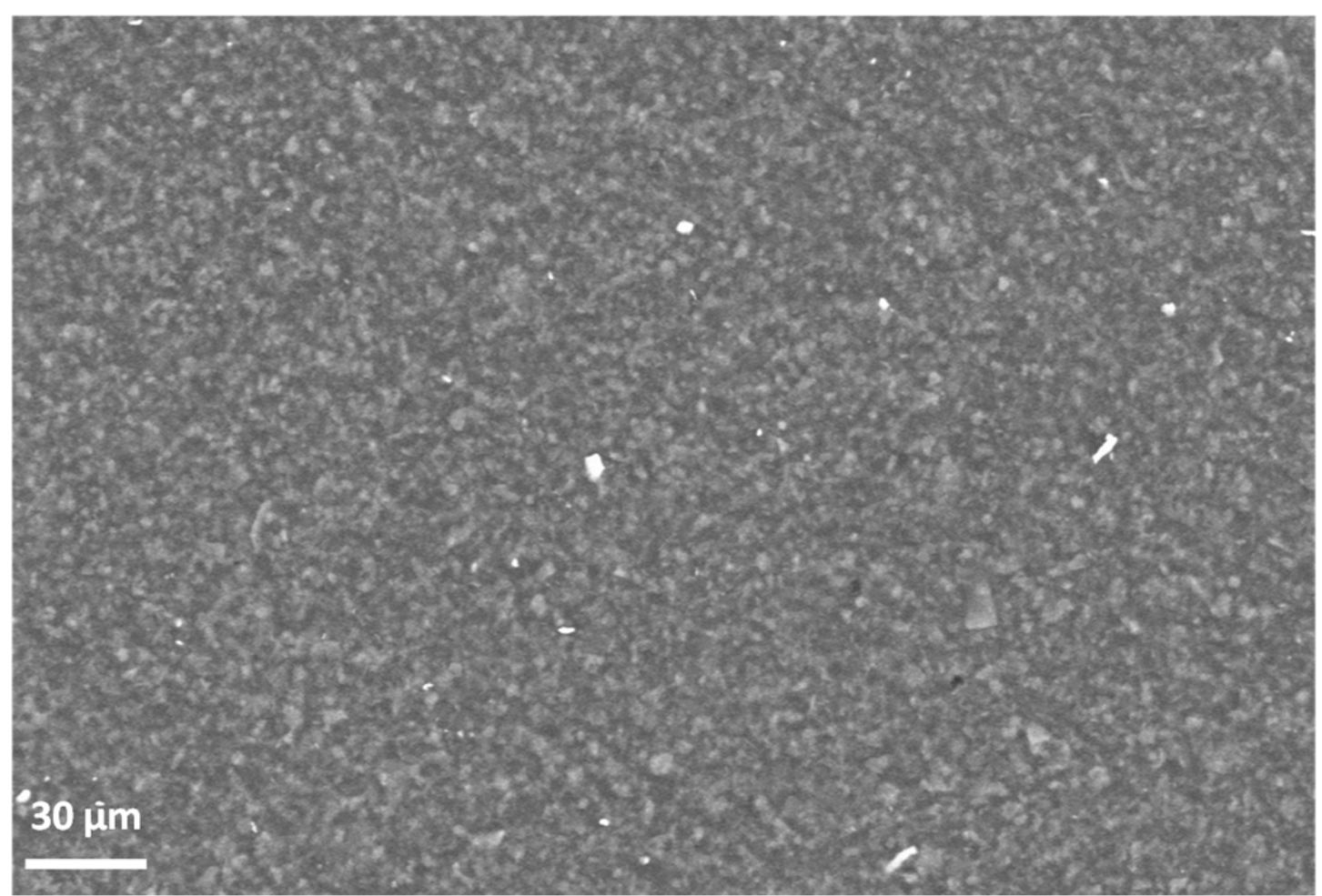

Figure 5(b): Backscattered SEM micrograph of PLA / Talc composite (70 / 30) 
(a)

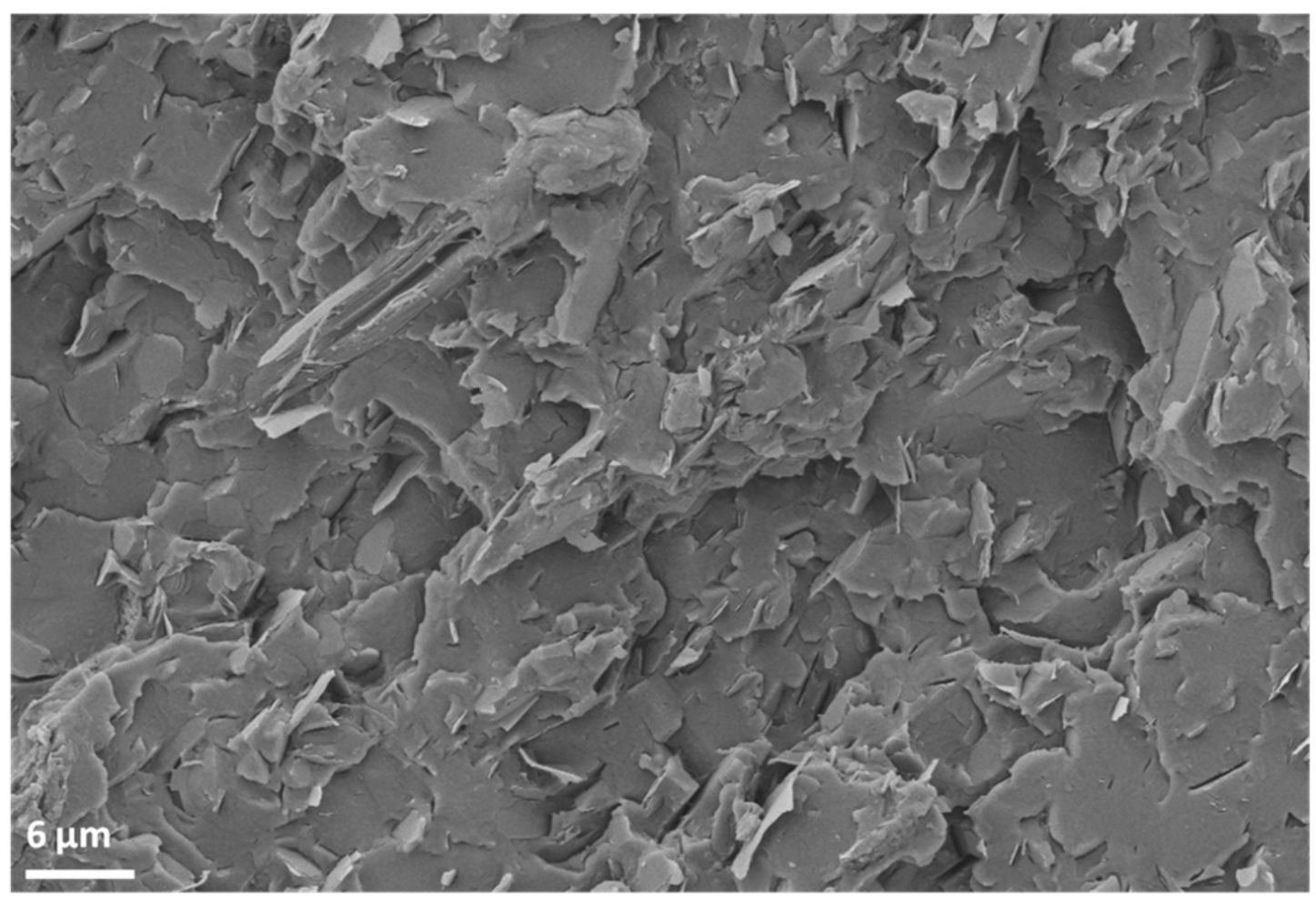

(b)

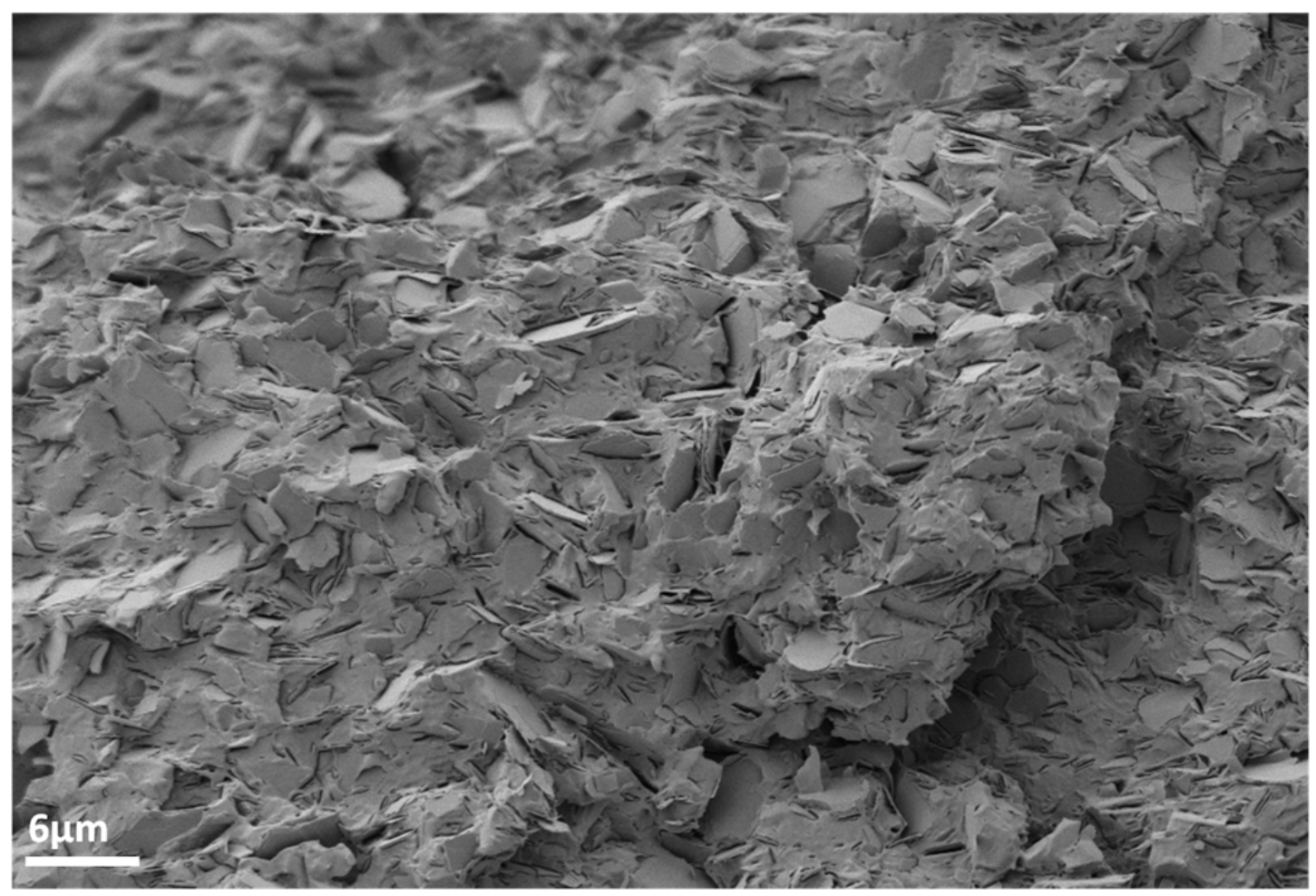


(c)

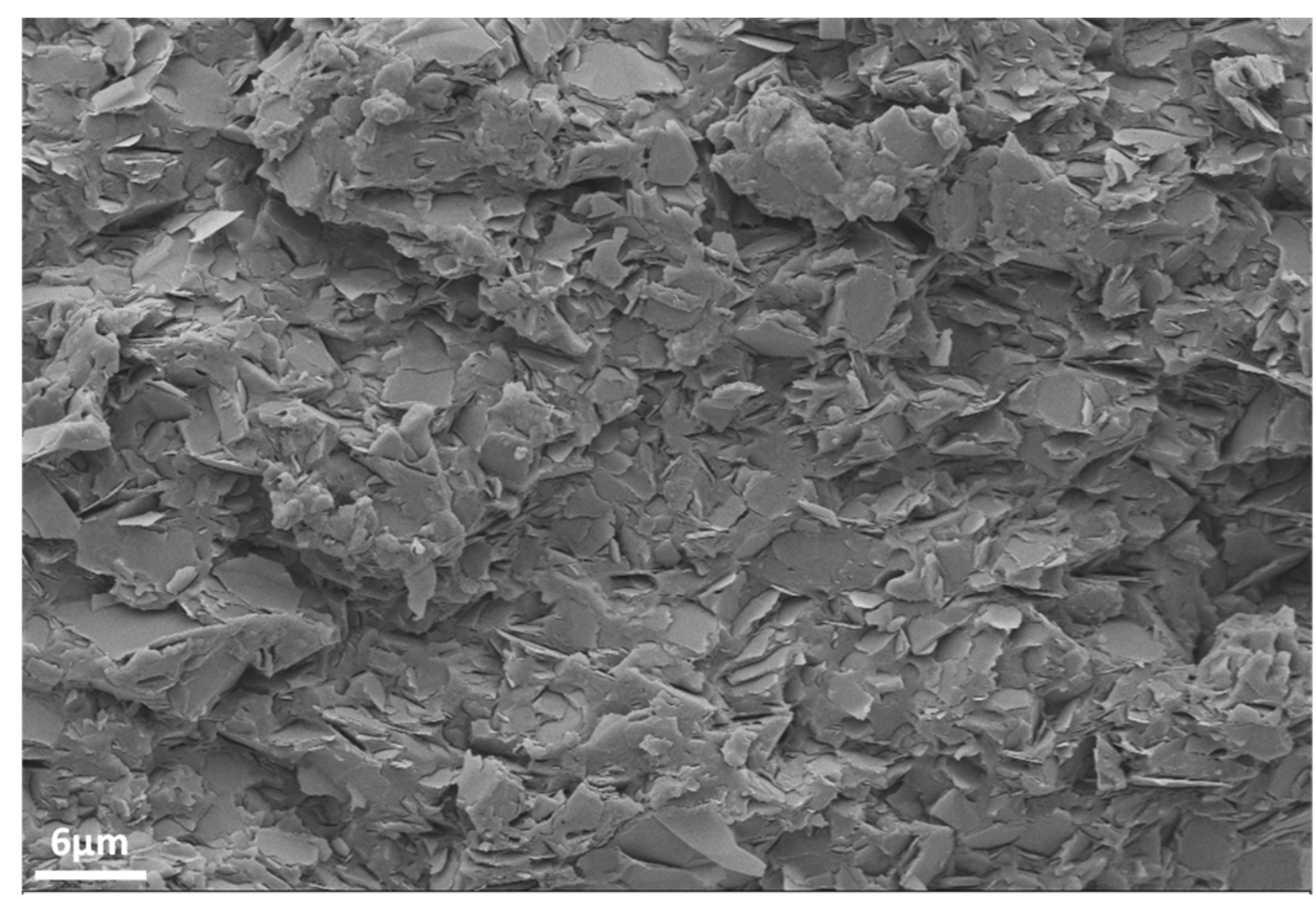

Figure 6: SEM Images of fracture surfaces of PLA / Talc Composites:

(a) $90 / 10$, (b) $80 / 20$, (c) $70 / 30$ 


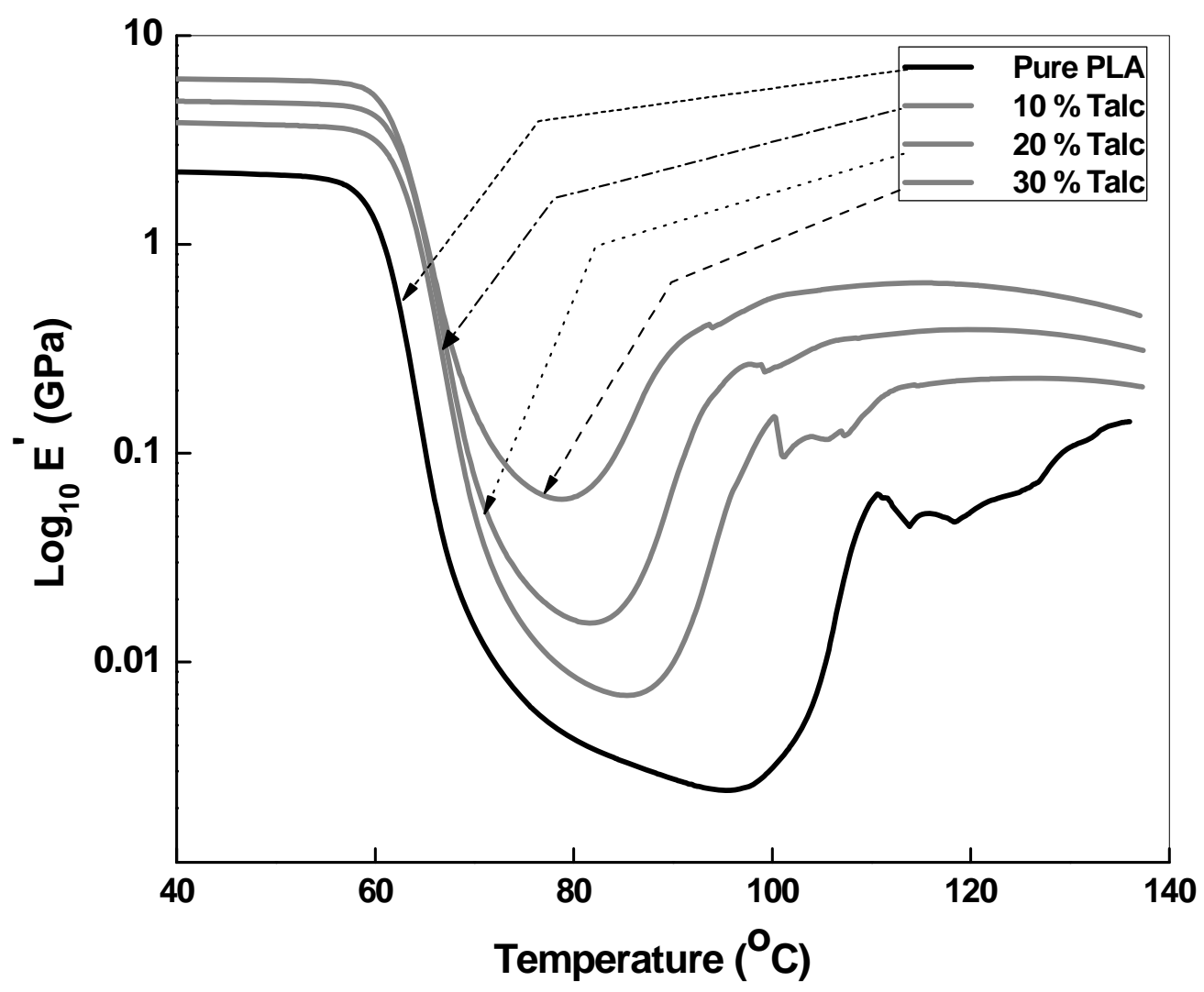

Figure 7: Storage Modulus as a Function of Temperature 


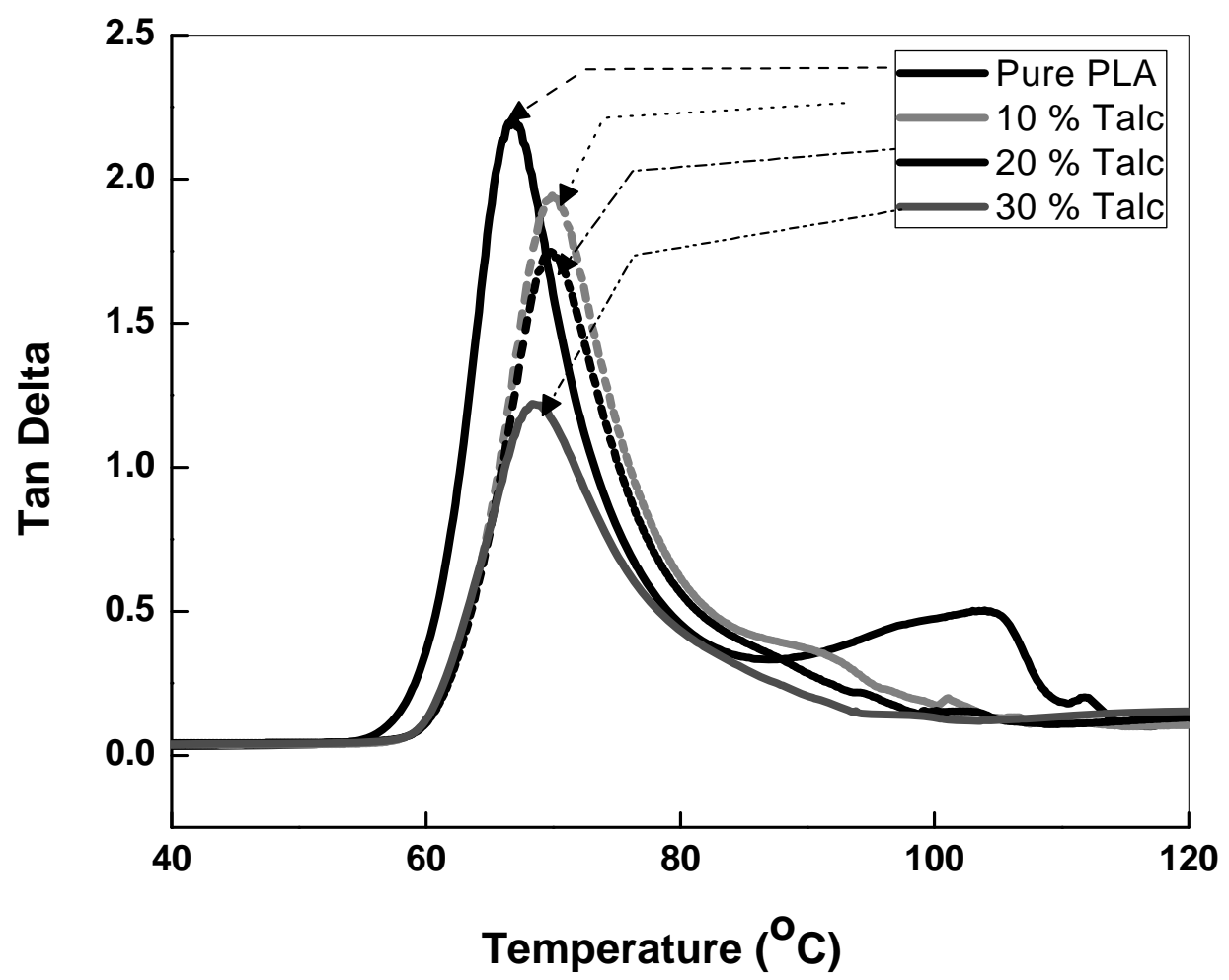

Figure 8: Tan Delta as a Function of Temperature 
Table 1: Glass Transition, Crystallization and Melting temperatures of PLA / Talc Composites

\begin{tabular}{|c|c|c|c|c|c|c|}
\hline $\begin{array}{c}\text { Sample } \\
\text { PLA / Talc }\end{array}$ & $T_{\mathrm{g}}$ & $\mathrm{T}_{\mathrm{c}}$ & \multicolumn{2}{|c|}{$\mathrm{T}_{\mathrm{m}}$} & $\begin{array}{c}\text { Cold - } \\
\text { Crystallization }\end{array}$ & Crystallinity \\
\hline$(\mathrm{wt} \%)$ & $\left({ }^{\circ} \mathrm{C}\right)$ & $\left({ }^{\circ} \mathrm{C}\right)$ & \multicolumn{2}{|c|}{$\left({ }^{\circ} \mathrm{C}\right)$} & $(\%)$ & $(\%)$ \\
\hline & & & $\alpha$ & $\beta$ & & $22 \pm 1.2$ \\
\hline $100 / 0$ & $54 \pm 0.7$ & $127 \pm 1.4$ & $155 \pm 1.4$ & --- & $2.0 \pm 0.8$ \\
\hline $90 / 10$ & $58 \pm 1.0$ & $96 \pm 1.0$ & $156 \pm 0.5$ & $149 \pm 0.1$ & $5.6 \pm 0.6$ & $25 \pm 0.5$ \\
\hline $80 / 20$ & $57 \pm 0.5$ & $95 \pm 0.4$ & $157 \pm 0.5$ & $150 \pm 0.5$ & $0.7 \pm 0.1$ & $25 \pm 0.9$ \\
\hline $70 / 30$ & $57 \pm 0.4$ & ---- & $157 \pm 0.2$ & $150 \pm 0.3$ & ----- & $27 \pm 0.1$ \\
\hline
\end{tabular}

Table 2: Tensile Properties of PLA / Talc Composites

\begin{tabular}{|c|c|c|c|}
\hline Sample PLA /Talc & Tensile Strength & Tensile Modulus & Elongation to break \\
\hline$(\mathrm{wt} \%)$ & $(\mathrm{MPa})$ & $(\mathrm{GPa})$ & $(\%)$ \\
\hline $100 / 0$ & $43.8 \pm 3.1$ & $4.1 \pm 0.6$ & $3.8 \pm 0.6$ \\
\hline $90 / 10$ & $38.0 \pm 2.4$ & $5.8 \pm 0.5$ & $3.0 \pm 0.8$ \\
\hline $80 / 20$ & $41.4 \pm 2.6$ & $7.0 \pm 0.6$ & $2.0 \pm 0.3$ \\
\hline $70 / 30$ & $44.6 \pm 3.7$ & $9.8 \pm 0.8$ & $2.0 \pm 0.6$ \\
\hline
\end{tabular}


Table 3: Thermo-mechanical properties of PLA / Talc composites

\begin{tabular}{|c|c|c|}
\hline $\begin{array}{c}\text { Sample } \\
\text { PLA / Talc }\end{array}$ & $\begin{array}{c}\text { Storage Modulus (Flexure) } \\
\left(30^{\circ} \mathrm{C}\right)\end{array}$ & $\begin{array}{c}\text { Glass Transition } \\
\left(\mathrm{T}_{\mathrm{g}}\right)\end{array}$ \\
\hline$(\mathrm{wt} \%)$ & $(\mathrm{GPa})$ & 66 \\
\hline $100 / 0$ & 2.3 & 70 \\
\hline $90 / 10$ & 3.9 & 70 \\
\hline $80 / 20$ & 4.9 & 69 \\
\hline $70 / 30$ & 6.2 & \\
\hline
\end{tabular}

